\title{
Antioxidant and Antimicrobial Activity of Polyphenol Extracts from Wild Berry Fruits Grown in Southeast Serbia
}

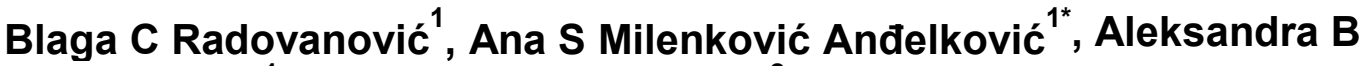 \\ Radovanović ${ }^{1}$ and Marko Z Anđelković ${ }^{2}$ \\ ${ }^{1}$ Department of Chemistry, Faculty for Mathematics and Science, University of Niš, Višegradska 33, 18000 Niš, ${ }^{2}$ CBRN \\ Training Center, Balkanska 57, 37000 Kruševac, Serbia \\ *For correspondence: Email: ana.andjelk@gmail.com; Tel: +381 16 218415; Fax: +381 18533014 \\ Received: 17 October 2012 \\ Revised accepted: 8 July 2013
}

\begin{abstract}
Purpose: To assess the antioxidant and antimicrobial activities of polyphenolic extracts of three wild red wild berry fruit species from Southeast Serbia, viz, European cornel (Cornus mas), blackthorn (Prunus spinosa L.) and wild blackberry (Rubus fruticosus).

Methods: Polyphenol content was determined using spectrophotometric and High performance liquid chromatography (HPLC) methods. Antioxidant activity was estimated by 2,2 - diphenyl - 1 picrylhydrazyl (DPPH) test while reliminary antimicrobial tests were carried out by disc diffusion method in which antibacterial activity was evaluated by measuring the zone of inhibition against test bacterial strains. Broth microdilution method was used to determine the minimum inhibitory concentration (MIC) and minimum bactericidal concentration (MBC).

Results: The highest amount of total phenols was found in European cornel (8625.89 $\mathrm{mg} \mathrm{kg}^{-1} \mathrm{FW}$ ). Galic acid, caffeic acid, p-coumaric acid, ferulic acid, (+)-catechin, procyanidin B2, (-)-epicatechin, quercetin, rutin and quercetin-3-glucoside were the main polyphenols in the fruit extracts. All extracts showed high scavenging effect on DPPH radical with $I C_{50}$ values ranging from 22.19 to $31.18 \mathrm{ml} \mathrm{g}^{-1}$, as well as high antimicrobial activity on almost all the tested bacterial strains.

Conclusion: Extracts of wild berry fruits may be suitable for the preparation of medicinal and nutritional products.
\end{abstract}

Keywords: European cornel, Blackthorn, Wild blackberry, Polyphenols, Antioxidant, Antimicrobial

Tropical Journal of Pharmaceutical Research is indexed by Science Citation Index (SciSearch), Scopus, International Pharmaceutical Abstract, Chemical Abstracts, Embase, Index Copernicus, EBSCO, African Index Medicus, JournalSeek, Journal Citation Reports/Science Edition, Directory of Open Access Journals (DOAJ), African Journal Online, Bioline International, Open-J-Gate and Pharmacy Abstracts

\section{INTRODUCTION}

Blackberry (Rubus fruticosus) is a perennial shrub, native to Europe. It prefers well-drained, loamy and moist soils. Blackberry is very tolerant of poor soils and was usually used to treat dysentery, diarrhea, hemorrhoids and cystitis in folk medicine [1-5]. It can be used as prevention against heart disease, cancer and eye degenerations. The leaves are useful in traditional phytotherapy treatments of wounds, sores, scratches, gum inflammations, ulcers and sore throat in Mediterranean countries [1-5].

Blackthorn (Prunus spinosa L.) is native to Europe, western Asia and Northwest Africa. Blackthorn is a deciduous large shrub or a small tree growing up to 5 meters in height. It is an excellent astringent. It can be used in the treatment of diarrhea. Its pectin components have a soothing and relaxing effect on stomach inflammation. An infusion of the plant can be used as a mild laxative in the treatment of 
constipation. Sloe berries can be used for stimulation of our metabolism, and can be of very good use in cases of eczema, herpes, allergies, colds, catarrh, indigestion, kidney stones, and skin and bladder disorders.

European Cornel (Cornus mas) is a deciduous shrub, growing 5 to 12 meters tall. The plant is native to south Europe and southwest Asia. Traditionally, European Cornel was applied in cases of fevers (bark, shoots, root) and diarrhea (fruit). Today, it is used for various ailments: stomach ache and cramps, diarrhea, different skin infections, intestinal parasites and hemorrhoids.

There are a number of studies on different fruit polyphenols and their antioxidant and antimicrobial activities, some of them include blackberry varieties [5-10] and no works of European Cornel and blackthorn polyphenols. Our aim was to determine and compare polyphenols, antioxidant and antimicrobial activities of those wild species.

\section{EXPERIMENTAL}

\section{Chemicals and materials}

Acetonitrile, and acetic acid of HPLC-grade were obtained from Merck (Darmstadt, Germany); HPLC-grade methanol were purchased from Carlo ERba Reagent (Milan, Italy); 2,2 - diphenyl - 1 - picrylhydrazyl (DPPH) free radical, gallic acid, caffeic acid, p-coumaric acid, ferulic acid, catechin, procyanidin B2, epicatechin, quercetin, rutin and quercetin-3-glucoside were supplied from Sigma Chemical Co. (St. Louis, MO, USA). The reagents were of analytical quality.

Samples of wild red fruits were collected in Vlasina region (Natural Park) which is located in Southeast Serbia. The climate of this region is typical of mountains with absolute maximum air temperature of $31.6^{\circ} \mathrm{C}$, and minimum of- $31.5^{\circ} \mathrm{C}$. Wild blackberry (Rubus fruticosus), European cornel (Cornus mas) and blackthorn (Prunus spinosa L.), were harvested at the commercial maturity stage in July - August 2011. Immediately after harvesting, the fruits were frozen and stored at $-20{ }^{\circ} \mathrm{C}$ until analysis.

Voucher specimens were deposited in the Herbarium of the Institute of Botany and Botanical Garden "Jevremovac", Faculty of Biology, University of Belgrade, under accession number 16634 (Cornus mas), 16635 (Prunus spinosa L.) and 16636 (Rubus fruticosus), BEOU [11]. The plant species were identified by Prof. dr Vladimir Ranđelović, Faculty of for Mathematics and Science, Department of Biology, University of Nis.

\section{Preparation of extracts}

The fresh fruits $(10 \mathrm{~g})$ were crushed in a grinder for $2 \mathrm{~min}$, extracted three times with $35 \mathrm{ml}$ acidifed methanol solution (formic acid/ methanol/water, $0.1 / 70 / 29.9, \quad v / v / v \%)$ in a magnetic stirrer for $24 \mathrm{~h}$ and then centrifuged for $10 \mathrm{~min}$ at $4000 \mathrm{rpm}$. Extracts were combined and purified through a $0.45 \mu \mathrm{m}$ syringe filter (Millipore) before analyses.

Determination of total phenols, tartaric esters, flavonols and free radical scavenging activity

Total phenols, tartaric esters and flavonols in fruit samples were determined spectrophotmetrically $[12,13]$. The dilute extract was mixed with $2 \%$ $\mathrm{HCl}$ in $95 \%$ ethanol approximately 15 min before reading the absorbance at 280, 320 and $360 \mathrm{~nm}$ with a UV/VIS Agilent 8453 spectrophotometer. The absorbance $(A)$ at $280 \mathrm{~nm}$ was used to estimate phenolics (gallic acid was used as standard), $A_{320 \mathrm{~nm}}$ was used to estimate hydroxycinnamoyl tartaric acids (caffeic acid was used as standard) and $A_{360 \mathrm{~nm}}$ was used to estimate flavonols (quercetin was used as standard).

The free radical scavenging activity of the wild fruit extracts was analyzed by using DPPH assay $[14,15]$. Antioxidant assay are based on measurement of the loss of DPPH color by change of absorbance at $517 \mathrm{~nm}$ caused by the reaction of $\mathrm{DPPH}$ with tested sample. The reaction was monitored by a UVIVIS spectrophotometer. The diluted extract and fresh $1 \times 10^{-4} \mathrm{M}$ DPPH metanolic solution were put into a cuvette at the room temperature. After $20 \mathrm{~min}$ incubation period at room temperature, the absorbance was read against a blank (the absorbance of diluted sample extract) at $517 \mathrm{~nm}$. Radical scavenging activity (RSA, \%) of each extract was calculated from the decrease of absorbance according to Eq 1.

$R S A(\%)=\left\{\left(1-A_{\text {sample }}-A_{\text {blank }}\right) /\left(A_{\text {control }}\right)\right\} 100 \ldots . .(1)$

where $A_{\text {control }}$ is the absorbance of control reaction, $A_{\text {blank }}$ is the absorbance of dilute extract and $A_{\text {sample }}$ is the absorbance of the extract with $\mathrm{DPPH}$ radical. The radical scavenging activity (\%) was plotted against the plant extract concentration $\left(\mathrm{ml} \mathrm{g}^{-1}\right)$ to determine the concentration of extract that reduces activity by $50 \%\left(\mathrm{EC}_{50}\right)$. 


\section{High performance liquid chromatography (HPLC) analysis}

Phenols were analyzed by direct injection of the extracts, previously filtered through a $0.45 \mu \mathrm{m}$ pore size membrane filter, in an Agilent Technologies 1200 chromatographic system equipped with a quaternary pump, an Agilent diode array detector 1200 with RFID tracking technology for flow cells and UV lamp and 1200 Fluorescence Detector for multi wavelength detection, on-line acquisition of Ex and Em spectra, 8ul flow cell, an automatic injector, and a ChemStation software. The column was thermostated at $30{ }^{\circ} \mathrm{C}$. After injecting $5 \mu \mathrm{L}$ of extract, separation was performed in an AgilentEclipse XDB C-18 $4.6 \times 150 \mathrm{~mm}$ column. The HPLC grade solvents used were formic $\mathrm{acid} /$ water as solvent $\mathrm{A}$ and acetonitrile/formic acid/water as solvent $B$. The elution profile was as follows: $0 \mathrm{~min}, 100 \% \mathrm{~A}, 0 \% \mathrm{~B} ; 10 \mathrm{~min}, 90 \%$ A, $10 \%$ B; 20 min, $80 \%$ A, $20 \%$ B; 30 min, 70 $\% \mathrm{~A}, 30 \% \mathrm{~B}: 35 \mathrm{~min}, 50 \% \mathrm{~A}, 50 \% \mathrm{~B} ; 40 \mathrm{~min}$, $20 \% A, 80 \%$ B. The system was equilibrated using the starting conditions for 10 min prior to injection of the next sample. The flow-rate was at $0.8 \mathrm{ml} \mathrm{min}^{-1}$ [13]. The detection wavelength were $280,320,322 / 275\left(\lambda_{E x} / \lambda_{E m}\right)$ and $360 \mathrm{~nm}$. Identification and quantitation of polyphenolic compounds were made by means of a calibration curve obtained with standard solutions of gallic acid, caffeic acid, p-coumaric acid, ferulic acid, catechin, procyanidin B2, epicatechin, quercetin, quercetin-3-glucoside and rutin. Results were expressed as $\mathrm{mg} \mathrm{kg}^{-1}$ fruit.

\section{ANTIMICROBIAL ACTIVITY}

The antimicrobial activity of the test samples was evaluated using the following laboratory control strains: Clostridium perfringens ATCC 19404, Bacillus subtilis ATCC 6633, Listeria innocua ATCC 33090, Staphylococcus aureus ATCC 6538, Sarcina lutea ATCC 9341 and Micrococcus flavus ATCC 40240 (Gram (+) bacteria), Escherichia coli ATCC 25922, Pseudomonas aeruginosa ATCC 9027, Salmonella enteritidis ATCC 13076, Shigella sonnei ATCC 25931, Klebsiella pneumoniae ATCC 10031 and Proteus vulgaris ATCC 8427 (Gram (-) bacteria) obtained from the American Type Culture Collection. The inocula of the bacterial strains were prepared from overnight broth cultures and suspensions were adjusted to $0.5 \mathrm{McF}$ arland standard turbidity (corresponding

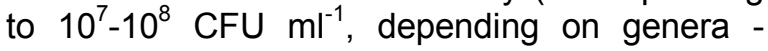
consensus standard by National Committee for Clinical Laboratory Standards (NCCLS).
Preliminary antimicrobial tests were carried out by disc diffusion method using $100 \mu \mathrm{l}$ of bacterial suspension spread on Mueller-Hinton agar (MHA, Torlak) in sterilized Petri dishes $(90 \mathrm{~mm}$ in diameter). The discs (9 $\mathrm{mm}$ in diameter, HiMedia Laboratories Pvt. Limited) were impregnated with $50 \mu \mathrm{l}$ of the testing samples and placed on the inoculated agar $(20 \mathrm{ml})$. The inoculated plates were incubated for $24 \mathrm{~h}$ at $37^{\circ} \mathrm{C}$. Reference antibiotics, chloramphenicol (30 $\mu \mathrm{g} / \mathrm{disc})$, streptomycin $(30 \mu \mathrm{g} /$ disc) and tetracycline (30 $\mu \mathrm{g} / \mathrm{disc}$ ) served as a positive control, while the solvent (water - $50 \mu \mathrm{l} / \mathrm{disc}$ ) was used as a negative control. The solvent (water) showed no inhibitory activity. All the tests were performed in triplicate. Antibacterial activity was evaluated by measuring the zone of inhibition (in $\mathrm{mm}$ ) against the test bacterial strains. A broth microdilution method was used to determine the minimum inhibitory concentration (MIC) and minimum bactericidal concentration (MBC) according to the National Committee for Clinical Laboratory Standards. The inocula of the bacterial strains were prepared from overnight broth cultures and suspensions were adjusted to 0.5 McFarland standard turbidity. A serial doubling dilutions of the testing samples were prepared in a 96/well microtiter plate over the range of $500-0.25 \mu \mathrm{ml}^{-}$ 1 in inoculated nutrient broth (the final volume $100 \mu \mathrm{l}$ and the final bacterial concentration was $10^{6} \mathrm{CFU} \mathrm{\textrm {mL } ^ { - 1 }}$ in each well). The plate was incubated for $24 \mathrm{~h}$ at $37^{\circ} \mathrm{C}$. All experiments were performed in triplicate. Two growth controls consisting of medium with water (negative control) and medium with chloramphenicol, streptomycin and tetracyclin (positive control) were also included. The microbial growth was determined by absorbance at $620 \mathrm{~nm}$ using the universal microplate reader (ThermoLabsystems, Multiskan EX, Software for Multiscan ver.2.6.). MIC was defined as the lowest concentration of test samples at which microorganisms showed no visible growth. In order to determine MBC, broth was taken from each well without visible growth and inoculated on Mueller Hinton agar (MHA) for $24 \mathrm{~h}$ at $37^{\circ} \mathrm{C}$. The MBC is defined as the lowest concentration of the test samples at which $99.9 \%$ of inoculated microorganisms were killed.

\section{Data analysis}

Three analytical replictes were carried out on each sample. The concentracion of phenolic compunds was measured and anlyzed using one-way ANOVA. Measurements were averaged, and results are given as mean \pm standard deviation (SD), calculated by analysis of variance using the Minitab statistical package, 
version 15 (Minitab Inc, State College, Pennsylvania, USA).

\section{RESULTS}

Total phenols, tartaric esters and flavonols content and radical scavenging activity in blackberry, European cornel and blackthorn extracts are presented in Table 1.
The concentrations of some phenolic and hydrxycinnamate acids, determinated using HPLC method, are shown in Table 2, while their contents of flavan-3-ols and flavonols are shown in Table 3.

The antimicrobial activity data for all investigated extract of wild berry fruits are given in Tables 4 and 5.

Table 1: Content of total phenols $\left(\mathrm{mg} \mathrm{GAE}^{\mathrm{a}} \mathrm{kg}^{-1}\right)$, tartaric esters $\left(\mathrm{mgCAE} \mathrm{kg}^{-1}\right)$, flavonols $\left(\mathrm{mg} \mathrm{QE}^{\mathrm{c}} \mathrm{kg}^{-1}\right)$ and radical scavenging activity of the wild fruit extracts, $E_{50}\left(\mathrm{ml} \mathrm{g}^{-1}\right)$

\begin{tabular}{|c|c|c|c|}
\hline Compound & Wild blackberry & Blackthorn & European cornel \\
\hline Total phenols & $7838.26 \pm 1.64$ & $7959.90 \pm 1.95$ & $8625.89 \pm 1.45$ \\
\hline Total tartaric esters & $291.91 \pm 1.83$ & $649.35 \pm 1.81$ & $625.45 \pm 1.46$ \\
\hline Total flavonols & $647.68 \pm 1.81$ & $971.69 \pm 0.66$ & $600.88 \pm 1.08$ \\
\hline Radical scavenging activity & $31.18 \pm 0.58$ & $27.06 \pm 0.80$ & $22.19 \pm 0.50$ \\
\hline
\end{tabular}

Table 2: Content of the phenolic and hydroxycinnamate acids of wild fruit extracts ( $\mathrm{mg} \mathrm{kg}^{-1}$ fresh weight)

\begin{tabular}{lccc}
\hline Compound & Wild blackberry & Blackthorn & European cornel \\
\hline Gallic acid & $137.98 \pm 1.23$ & $150.21 \pm 1.14$ & $443.53 \pm 1.25$ \\
$t$ - Caftaric acid & $0.99 \pm 0.70$ & $20.65 \pm 0.25$ & $4.97 \pm 0.56$ \\
$t$ - Coutaric acid & - & $7.88 \pm 0.94$ & - \\
Caffeic acid & $0.33 \pm 0.11$ & $0.34 \pm 0.07$ & $12.51 \pm 0.23$ \\
Sirginic acid & $3.71 \pm 0.25$ & $48.14 \pm 2.14$ & $11.98 \pm 1.15$ \\
p-Coumaric acid & - & - & $48.75 \pm 1.34$ \\
\hline Values are the means \pm standard deviation $(n=3)$ & &
\end{tabular}

Table 3: Content of flavan-3-ols: procyanidin B2, (+) - catechin and (-) - epicatechin at 322/275 nm $\left(\lambda_{E x} / \lambda_{E m}\right)$ and flavonols: quercetin-3-glucoside, rutin and quercetin expressed as $\mathrm{mg} \mathrm{kg}^{-1}$ fresh weight

\begin{tabular}{lccc}
\hline Compound & Wild blackberry & Blackthorn & European cornel \\
\hline Procyanidin B2 & $1.49 \pm 0.22$ & $14.51 \pm 1.97$ & $1.61 \pm 0.34$ \\
(+)-Catechin & $4.09 \pm 0.95$ & $6.42 \pm 1.03$ & $3.95 \pm 0.77$ \\
(-)-Epicatechin & $3.63 \pm 0.49$ & $3.39 \pm 0.58$ & $4.02 \pm 0.64$ \\
Quercetin-3-Glycoside & $3.53 \pm 0.16$ & $32.02 \pm 1.42$ & $12.02 \pm 1.36$ \\
Rutin & $22.77 \pm 1.98$ & $13.86 \pm 1.44$ & $13.86 \pm 1.44$ \\
Quercetin & $3.79 \pm 0.63$ & $1.16 \pm 0.21$ & $0.65 \pm 0.29$ \\
\hline Values are the mean \pm standard deviation $(n=3)$ & &
\end{tabular}

Table 4: Diameters of inhibition zone (in $\mathrm{mm}$ ) for the extracts $\left(50 \mu \mathrm{L}\right.$ disc $\left.^{-1}\right)$

\begin{tabular}{|c|c|c|c|c|c|c|}
\hline Bacterial strain & Blackthorn & $\begin{array}{l}\text { European } \\
\text { cornel }\end{array}$ & $\begin{array}{c}\text { Wild } \\
\text { blackberry }\end{array}$ & $\mathrm{St}^{\mathrm{a}}$ & $\begin{array}{c}\text { Antibiotics } \\
\left(30 \mu g \text { disc }^{-1}\right) \\
\mathbf{C h}^{\mathrm{b}}\end{array}$ & Tet. $^{\mathrm{c}}$ \\
\hline \multicolumn{7}{|l|}{ Gram negative } \\
\hline Escherichia coli & $15.6 \pm 1.3$ & $15.8 \pm 0.9$ & $14.2 \pm 3.1$ & $16.0 \pm 1.2$ & nt & $23.2 \pm 1.2$ \\
\hline Pseudomonas aeruginosa & $12.9 \pm 1.1$ & $13.6 \pm 2.4$ & $13.4 \pm 2.3$ & $23.0 \pm 1.0$ & nt & $20.8 \pm 1.5$ \\
\hline Salmonella enteritidis & $15.7 \pm 1.6$ & $14.3 \pm 3.1$ & $14.0 \pm 0.9$ & $18.0 \pm 1.0$ & nt & $23.3 \pm 1.3$ \\
\hline Shigella sonnei & $15.9 \pm 1.7$ & $15.4 \pm 2.5$ & $15.9 \pm 1.6$ & $19.0 \pm 2.0$ & nt & $31.1 \pm 0.8$ \\
\hline Klebsiella pneumoniae & 0 & 0 & 0 & $\mathrm{nt}$ & $\mathrm{nt}$ & $23.6 \pm 0.6$ \\
\hline Proteus vulgaris & $13.3 \pm 0.7$ & $13.4 \pm 1.9$ & 0 & $\mathrm{nt}$ & nt & $19.2 \pm 0.5$ \\
\hline \multicolumn{7}{|l|}{ Gram-positive } \\
\hline Clostridium perfringens & $13.8 \pm 1.1$ & $12.2 \pm 2.0$ & $12.1 \pm 1.0$ & $\mathrm{nt}$ & $\mathrm{nt}$ & $29.0 \pm 2.0$ \\
\hline Bacillus subtillis & $12.6 \pm 1.1$ & $13.7 \pm 1.2$ & $14.2 \pm 1.3$ & $\mathrm{nt}$ & $26.0 \pm 1.1$ & $23.9 \pm 1.0$ \\
\hline Staphylococcus aureus & $14.2 \pm 2.2$ & $14.8 \pm 2.0$ & $13.7 \pm 1.3$ & $\mathrm{nt}$ & $25.0 \pm 1.2$ & $18.5 \pm 1.3$ \\
\hline Listeria inocua & $12.4 \pm 1.8$ & $13.1 \pm 1.8$ & $12.0 \pm 1.0$ & $\mathrm{nt}$ & $18.0 \pm 2.0$ & $18.7 \pm 1.2$ \\
\hline Sarcina lutea & $14.7 \pm 1.6$ & $14.7 \pm 1.8$ & $13.8 \pm 1.6$ & nt & $38.0 \pm 2.0$ & $20.0 \pm 1.2$ \\
\hline Micrococcus flavus & $14.0 \pm 1.2$ & $12.9 \pm 1.8$ & $16.2 \pm 1.4$ & $\mathrm{nt}$ & $35.0 \pm 2.1$ & $23.6 \pm 0.7$ \\
\hline
\end{tabular}


Table 5: Antibacterial (MIC) and bactericidal (MBC) activities of extracts and reference antibiotics $\mathrm{MIC} / \mathrm{MBC}(\mu \mathrm{g}$ $\left.\mathrm{ml}^{-1}\right)$

\begin{tabular}{|c|c|c|c|c|c|c|}
\hline Bacterial strain & Blackthorn & $\begin{array}{l}\text { European } \\
\text { cornel }\end{array}$ & $\begin{array}{l}\text { Wild } \\
\text { blackberry }\end{array}$ & $\begin{array}{l}\text { Antibi } \\
\text { St. }^{a}\end{array}$ & $\mathrm{Ch}^{\mathrm{b}}$ & Tet. $^{\mathrm{c}}$ \\
\hline \multicolumn{7}{|l|}{ Gram negative } \\
\hline Escherichia coli & $250 / 500$ & $250 / 500$ & $500 / 500$ & $16 / 16$ & nt & $3.8 / 7.5$ \\
\hline Pseudomonas aeruginosa & $125 / 125$ & $500 / 500$ & $250 / 250$ & $8 / 8$ & nt & $7.5 / 7.5$ \\
\hline Salmonella enteritidis & $250 / 250$ & $62.5 / 125$ & $62.5 / 62.5$ & $4 / 4$ & $\mathrm{nt}$ & $0.9 / 1.9$ \\
\hline Shigella sonnei & $125 / 125$ & $250 / 250$ & $250 / 250$ & $16 / 16$ & nt & $0.06 / 0.12$ \\
\hline Klebsiella pneumoniae & $125 / 125$ & $250 / 250$ & $500 / 500$ & nt & $\mathrm{nt}$ & $0.9 / 1.9$ \\
\hline Proteus vulgaris & $125 / 125$ & $250 / 500$ & $500 / 500$ & $\mathrm{nt}$ & nt & $1.9 / 1.9$ \\
\hline \multicolumn{7}{|l|}{ Gram-positive } \\
\hline Clostridium perfringens & $125 / 125$ & $125 / 250$ & $500 / 500$ & $\mathrm{nt}$ & $1 / 8$ & $0.9 / 0.9$ \\
\hline Bacillus subtillis & $250 / 250$ & $62.5 / 125$ & $500 / 500$ & $\mathrm{nt}$ & $8 / 8$ & $0.9 / 0.9$ \\
\hline Staphylococcus aureus & $15.6 / 125$ & $125 / 125$ & $62.5 / 125$ & $\mathrm{nt}$ & $2 / 16$ & $0.12 / 0.9$ \\
\hline Listeria inocua & $31.2 / 31.2$ & $125 / 125$ & $500 / 500$ & $\mathrm{nt}$ & $8 / 18$ & $0.46 / 0.9$ \\
\hline Sarcina lutea & $62.5 / 62.5$ & $62.5 / 62.5$ & $125 / 125$ & $\mathrm{nt}$ & $0.5 / 2$ & $0.06 / 0.06$ \\
\hline Micrococcus flavus & $125 / 125$ & $250 / 250$ & $250 / 250$ & $\mathrm{nt}$ & $1 / 1$ & $0.4 / 0.9$ \\
\hline
\end{tabular}

- Streptomycin; ${ }^{b}$ - Chloramphenicol; ${ }^{c}$ - Tetracyclin; $n t$ - not tested

\section{DISCUSSION}

The results show high concentrations of total phenols in all the fruit extracts which is in agreement with literature data (concentration of total phenols ranged from $3610-7580 \mathrm{mg}$ GAE $\mathrm{kg}^{-1} \quad$ FW for blackberry cultivars and wild genotypes) [6,7,16]. Gallic acid was the predominant acid in all fruit extracts. By contrast, t-caftaric acid, t-coutaric acid, caffeic acid, sirginic acid, and p-coumaric acid were the least abundant phenolic acids in all investgated extracts. (+) - catechin was the predominant falavan-3-ol, which represented the $44.40 \%$ of the total flavan-3-ols content, than (-) epicatechin (39.41\%) and procyanidin B2 (16.17 $\%$, in wild blackberry. In Blackthorn, the procyanidin B2 $(59.66 \%)$ was the predominant falavan-3-ol, than (+) - catechin $(26.39 \%)$ and (-) - epicatechin (13.93\%). In European cornel was found almost identical content of $(+)$ - catechin and $(-)$ - epicatechin $(41.23 \%, 41.96 \%$, respectively) and lower content of procyanidin B2 $(16.80 \%)$. Similar flavan-3-ols composition in red fruits found other authors where $(+)$ - catechin and $(-)$ - epicatechin were predominant flavan-3ols also $[17,18]$.

The highest concentration of quercetin-3glucoside was found in blackthorn extract, while rutin and quercetin were the predominant flavonols in blackberry extract. The data presented by other authors show that the main flavonols in red fruits are quercetin glucosides and quercetin $[8,17,18]$. The highest total flavonols content was found in blackthorn, followed by wild blackberry and European cornel, which is in good agreement with results gotten by spectrophotometric method.
There are a number of reports on the antioxidant activities of fruit extracts determined by several methods $[9,10,19,20]$. In order to evaluate antioxidant activity of wild red fruits, DPPH assay was applied. The European cornel, with the lowest $\mathrm{EC}_{50}$ value, indicted the highest $\mathrm{DPPH}$ savenging activity, followed by blackthorn and wild blackberry. Total phenols were found to correlate negatively with the $\mathrm{EC}_{50}$ values and significantly $(r=-0.9455, p<0.01)$. The total tartaric esters and total flavonols correlate with with the $\mathrm{EC}_{50}$ values also, but lower than total phenols $(r=-0.7578$ and $-0.6158, p<0.05$, respectively), which is in agreement with data presented by others [9,10,21-23]. The strong negative correlation was found between total acids and the $\mathrm{EC}_{50}$ values $(r=-0.9673, p<0.01)$ and also between individual acids and the $\mathrm{EC}_{50}$ values (gallic acid, $r=-0.9047$ ). Rutin showed good correlation with the $E_{50}$ values $(r=-$ $0.7991) \backslash$ followed by $(-)$-epicatechin $(r=-0.6505)$ and quercetin $(r=-0.6131)$. The correlation between the $\mathrm{EC}_{50}$ values and the other investigated phenolic compounds was low.

The antimicrobial activity of the extracts was high against almost all the tested bacterial strains. Inhibition zones of the tested wild fruits $(50 \mu \mathrm{l}$ disc $^{-1}$ ) were in the range from $12.0-16.2 \mathrm{~mm}$. In addition, for most of the extracts, lack of activity against $K$. pneumoniae was noticed, which was not confirmed by microdilution method results. Among Gram (-) bacteria, the most sensitive was $S$. enteritidis, while in the group of Gram+ bacteria, it was $S$. aureus. It can be noticed that blackthorn extract possess slightly higher antimicrobial activity in comparison to the other tested samples. Also, it must be pointed out that in the cases of almost all tested samples, MIC was equal to $\mathrm{MBC}$, meaning that determined 
critical concentration of antimicrobial compounds has mostly bactericidal activity.

\section{CONCLUSION}

All investigated extracts of wild berry fruits contain high polyphenol concentration and show high antioxidant activity. The extracts also show strong antimicrobial activity, mainly antibacterial, against almost all the test bacterial strains. These activities of wild berry fruits could be exploited for the preparation of medicinal and nutritional products.

\section{ACKNOWLEDGEMENT}

The research was supported by the European Union, FP7 - REGPOT - 2007- 3-01, KBBE: Food, Agriculture, and Biotechnology, Project «CHROMLAB-ANTIOXIDANT», no. 204756 and by Ministry of Science of Serbia, Project no.031020.

\section{REFERENCES}

1. Panizzi L, Caponi C, Catalano S, Cioni PL, Morelli I. In vitro antimicrobial activityof extracts and isolated constituents of Rubus ulmifolius. Ethnopharmacol 2002; 79: 165-168.

2. Martini $S$, D'Addario $C$, Colacevich $A$, Focardi $S$ Borghini F, Santucci A, Figura N, Rossi C. Antimicrobial activity against Helicobacter pyloristrains and antioxidant properties of blackberry leaves (Rubus ulmifolius) and isolated compounds. Int J Antimicrob Ag 2009; 34: 50-59.

3. Guarrera PM. Traditional phytotherapy in central Italy (Marche, Abruzzo, andLatium). Fitoterapia 2005, 76: 1-25.

4. Erdemoglu N, Kupeli E, Yesilada E. Anti-inflammatory and antinociceptive activityassessment of plants used as remedy in Turkish folk medicine. J Ethnopharmacol2003; 89: 123-129.

5. Patel AV, Rojas-Vera J, Dacke CG. Therapeutic constituents and actions of Rubus species. Curr Med Chem 2004; 11: 1501-1512.

6. Sellappan S, Akoh CC, Krewer G. Phenolic compounds and antioxidant capacity of Georgia-grown blueberries and blackberries. J Agric Food Chem 2002; 50:2432-2438.

7. Reyes-Carmona J, Yousef GG, Martínez-Peniche RA, Lila MA. Antioxidant capacity of fruit extracts of blackberry (Rubus sp.) produced in different climatic regions. J Food Sci 2005; 70: 497-503

8. Määttä-Riihinen $K R$, Kamal-Eldin $A$, Törrönen $A R$. Identification and Quantification of Phenolic compounds in berries of Fragaria and Rubus species (Family Rosaceae). J Agric Food Chem 2004; 52: 6178-6187.

9. Moyer RA, Hummer KE, Finn CE, Frei B, Wrolstad RE. Anthocyanins, phenolics, and atioxidant capacity in diverse small fruits: Vaccinium, Rubus, and Ribes. J Agr Food Chem 2002; 50: 519-525.

10. Bermudez-Soto M, Tomas-Barberan FA. Evaluation of commercial red fruit juice concentrates as ingredients for antioxidant functional juices. Eur Food Res Technol 2004; 219: 133-141.

11. BEOU, Holmgren PK, Holmgren NH, Barnett LC.Index Herbariorum. Part 1. The Herbaria of the World, 1990; $p 16476$.

12. Mazza G, Fukumoto $L$, Delaquis $P$, Girard B, Ewert $B$. Anthocyanins, Phenolics, and color of cabernet Franc, Merlot, and Pinot Noir wines from British Columbia. J Agric Food Chem 1999; 47: 40094017.

13. Radovanovic $B C$, Radovanovic AN, Souquet JM. Phenolic profile and free radical-scavenging activity of Cabernet Sauvignon wines of different geographical origins from the Balkan region. J Sci Food Agric 2010; 90: 2455-2461.

14. Choi CW, Kim SC, Hwang SS, Choi BK, Ahn HJ, Lee MY, Park SH, Kim K Antioxidant activity and free radical scavenging capacity between Korean medicinal plants and flavonoids by assay-guided comparison. Plant Sci 2002; 163: 1161-68.

15. Munoz-Espada A, Wood K, Bordelon B, Watkins $B$. Anthocyanin Quantification and radical scavenging capacity of Concord, Norton and Marechal Foch grapes and wines. J Agric Food Chem 2004; 52: 6779-6786

16. Heinonen IM, Meyer AS, Frankel EN. Antioxidant activity of berry phenolics on human low-density lipoprotein and liposome oxidation. J Agric Food Chem 1998; 46:4107-4112.

17. Tomas-Barberan FA, Clifford MN. Dietary hydroxybenzoic acid derivatives-nature, occurrence and dietary burden. J Sci Food Agr 2000; 80: 10241032.

18. Määttä-Riihinen $K R$, Kamal-Eldin $A$, Mattila $P H$, Gonzalez-Paramas AM, Törrönen AR. Distribution and contents of phenolic compounds in eighteen Scandinavian berry species. J Agric Food Chem 2004; 52: 4477-4486.

19. Häkkinen S, Heinonen $M$, Kärenlampi S, Mykkänen $H$, Ruuskanen J, Törrönen R. Screening of selected flavonoids and phenolic acids in 19 berries. Food Res Int 1999; 32: 345-353.

20. Wu X, Gu L, Prior RL, McKay S. Characterization of anthocyanins and proanthocyanins in some cultivars of Ribes, Aronia, and Sambucus and their antioxidant capacity. J Agr Food Chem 2004; 52: 7846-7856.

21. Korekar G, Stobdan T, Arora R, Yadav A, Singh SB. Antioxidant capacity and phenolics content of apricot (Prunus armeniaca L.) Kernel as a Function of Genotype Plant Foods Hum Nutr 2011; 66:376383.

22. Prior RL, Clark JR, Brownmiller C. Antioxidant capacity as influenced by total phenolic and anthocyanin content, maturity, and variety of Vaccinium species. J Agr Food Chem 1998; 46: 2686-2693.

23. Howard LR, Clark JR, Brownmiller C. Antioxidant capacity and phenolic content in bluebrries as affected by genotype and growing season. J Sci Food Agr 2003; 83: 1238-1247. 